九州大学学術情報リポジトリ

Kyushu University Institutional Repository

\title{
Relationship between Sea Ice Thickness and Temperature in Bohai Sea of China
}

Li, Ning

China Key Laboratory of Environmental Changes and National Disaster of Ministry of Education, College of Resources Science and Technology, Beijing Normal University

Maki, Taichi

Hayakawa, Se i j i

Department of Biological and Environmental Sciences, Faculty of Agriculture, Yamaguchi University

https://doi.org/10.5109/4634

出版情報：九州大学大学院農学研究院紀要. 50 (1)，pp. 165-173，2005-02-01. Faculty of Agriculture, Kyushu University

バージョン：

権利関係 : 


\title{
Relationship between Sea Ice Thickness and Temperature in Bohai Sea of China
}

\author{
Ning LI $^{1}$, Wei GU ${ }^{1 *}$, Taichi MAKI and Seiji HAYAKAWA ${ }^{2}$ \\ Laboratory of Applied Meteorology, Division of Regional Environment Science, \\ Department of Bioproduction Environmental Sciences, Faculty of \\ Agriculture, Kyushu University, Fukuoka 812-8581, Japan \\ (Received August 25, 2004 and accepted November 11, 2004)
}

\begin{abstract}
To discover water sources of agriculture irrigation for regions around Bohai Sea in China, sea ice in Bohai Sea is considered as the new kind of fresh water resource due to its lower salinity than seawater, and the thermal characteristics of sea ice thickness affected by accumulative temperature were analyzed in the paper. The tentative results showed that the ice thickness growth is proportional to time in a second-degree polynomial under air temperature lower than $-1.4^{\circ} \mathrm{C}$. Before $39^{\text {th }}$ hour, ice thickness increased very quickly, with a speed of $1.5 \mathrm{~mm} / \mathrm{h}$, and after the $40^{\text {th }}$ hour, its growth speed had decreased and maintained at approximately $0.24 \mathrm{~mm} / \mathrm{h}$. The linear model was useful to study sea ice thickness and its evolution in the seasonal ice cover of Bohai Sea by an negative accumulated air temperature with $\leq-2{ }^{\circ} \mathrm{C}$ at $15 \mathrm{~cm}$ height above ice surface with $R^{2}=0.9262$ and 0.9044 in winter of 2003 and 2004 .
\end{abstract}

\section{INTRODUCTION}

The Bohai Sea $\left(117.5^{\circ}-121.1^{\circ} \mathrm{E}, 37.1^{\circ}-41.9^{\circ} \mathrm{N}\right)$ is of mid-latitude and inner sea of the northeast coast of China. China's per capita possession of fresh water resource stands at a mere 2,200 cubic meters, nearly one quarter of the world average. The regions around seacoast of Bohai Ses are the important industrial and agricultural center and with dense population, the level is even lower at less than 500 cubic meters. Since water shortage has been a key point that severely restricts the regional economy and social development for the regions, finding a new fresh water resource for these regions is an area of intense interest.

China is planning to take seawater desalinization as an essential means to overcome its current water shortage problem. For the present, the importance of seawater freshening has not yet been fully recognized by relevant decision-making departments, while the State has not made sufficient investment in the research and development of seawater desalting technologies.

Bohai coastlines accumulate ice only periodically, unlike other coastlines facing the Arctic Ocean, which is normally ice covered for three months in the winter from December this year to February the following year. The ice usually was called as first-year ice (Wu and Leppäranta, 1988). Since sea ice acts as a barrier to the transfer of

1 China Key Laboratory of Environmental Changes and Natural Disaster of Ministry of Education, College of Resources Science and technology, Beijing Normal University, Beijing 100875, China

2 Department of Biological and Environmental Sciences, Faculty of Agriculture, Yamaguchi University, 1677-1 Yoshida, yamaguchi 753-8515, Japan

* Corresponding author (E-mail: weigu@bnu.edu.cn) 
moisture, heat, and momentum between the atmosphere and the ocean, sea ice research efforts are being devoted to model the seasonal ice climate (Haapala and Leppäranta, 1996), ice dynamics investigations (Heveder, 2001), ice thermodynamics and air-ice interaction (Worby, 2002). However, ice formation rejects incorporation of salt, sea ice has lower salinity when compared with seawater. The process to desalt sea ice, hence, will be easier than seawater. Due to the characteristic of lower salinity sea ice utilize as a potential resource of fresh water to be considered in this paper. Some tentative plans have been provided for using the sea ice resource during these years (Gu et al., 2002; Shi et al., 2002). These plans proved that the technologies could transform sea ice into fresh water with simpler treatment and lower cost, and the treated fresh water achieved its quality standard can then be used to agricultural irrigation. These tentative plans raised many interesting questions, foremost being whether the amount of the first-year ice could be enough to be used as a new source of freshwater for exploitation for future agricultural irrigation under a global warming scenario. To estimate the amount of sea ice, the actual estimation is focused on the area and the thickness of sea ice. However, sea ice thickness, among all parameters of sea ice, is the hardest one to obtain. At presently, the direct ways to survey and measure sea ice reserve are very scarce and costly, mainly dependent on remote sensing. However, due to the lack of information and no direct means in obtaining from remote sensing imagery, sea ice thickness can only be obtained only using a indirect method, utilizing the relationship of ice thickness and parameters on the ice surface. The indirect factors include temperature, the reflectivity, and thermodynamic characters of sea ice. Understanding the changing characteristics of sea ice thickness affected by these factors is the basis for estimation of the amount of sea ice resources.

The characteristic of remote sensing is that monitor ice condition in rapid speeds and large area based on the analysis and treatment the reflectivity ice surface. Especially, in the discriminative analysis for ice area, remote sensing method has the obvious superiority compared with other methods. Therefore, the estimated study on sea ice resources mainly focuses on the remote sensing recently. However, there are two key problems in estimating sea ice resources using remote sensing in Bohai Sea. First, the base to estimate sea ice thickness by data of AVHRR is dependent on the relation between reflectivity and ice thickness, which is Reduced by some other country's researcher according to their experiment result from other sea area. The relation is not confirmed to be useful in Bohai area in China. Second, large area and short-term (24h) observational data of sea ice obtained from icebreaker in Bohai region is rare. Even if these data (for example, a characteristics observation in Liaodong Bay made by a icebreaker of state ocean bureau in Jan. 18, 2000) exist, its reliability was affected seriously due to the cloud cover above the sea region at on that observation day. Therefore, the precision of estimating of remote sensing is hard to be valid. From this point of view, Bohai Sea ice characteristics need to be studied in a large scale and in a long-term in order to be validated.

Previous research on sea ice as the fresh water resources mainly aim at desalting mechanism, desalt method and estimating the sum of sea ice (Shi, 2002; Gu, 2002) by remote sensing. However, the variation of ice thermal properties, the phase change in ice growth and melting are the main topics of sea ice thermodynamic. In this paper, a case study was conducted in the Bohai Bay region, to investigate icing process with various 
thermal properties and the thermodynamic characters of sea ice thickness.

\section{MATERIALS AND METHODS}

\section{General aspects of sea ice in Bohai Sea}

Sea ice is a product of the thermodynamic interaction between the cold atmosphere and the underlying ocean (Cheng, 2002). The ocean-atmosphere heat exchange is very sensitive to the thin portion of the sea ice thickness distribution (Rothrock, 1999). Sea ice in Bohai Sea is the first year sea ice. It forms from December of one year, melts after February of the immediate next year, and retreat in the next winter as caused by large-scale weather system changes. Although water depth and distance from coast belong to the geographical index, it is related to thermal capacity of ocean. Under the same air temperature, the deeper the seawater is, the larger the thermal capacity of ocean, and the slower the sea ice growth (GU, 2002). The sea ice in Bohai Sea begins to occur from the shallow sea area close to coast, than develop and extend to deeper sea area gradually. The ice thickness distribution obviously represents the characteristics decreasing from coast to center of ocean on normal year (Fig. 1).

The seawater in the region has $29-30 \%$ salinity, and freeze point is $-1.4^{\circ} \mathrm{C}$. On normal ice year, the average thickness of fixed ice range from 15 to $40 \mathrm{~cm}$, and the width range from 1 to $4 \mathrm{~km}$ (Bao, 1999); the drifting ice with $10-25 \mathrm{~cm}$ thickness (Wu, 1999). The area of fixed and drifting ice in heavy ice period could cover the whole Liaodong Bay and a part of laizhou Bay (Fig. 1). It indicates that sea ice in Bohai Sea is characterized by expansion in an extensive area, thinness, drifting activity and asymmetrical distribution.

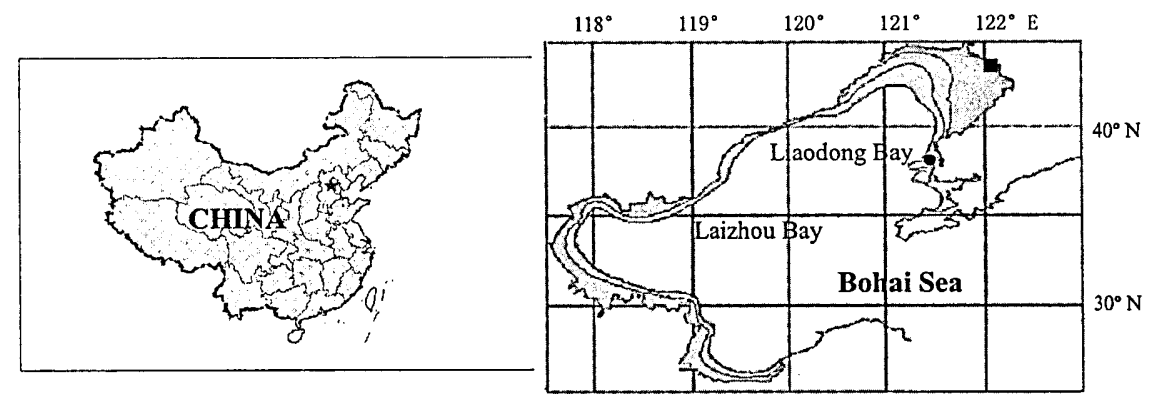

Fig. 1. Location of observation site in Bohai Sea of China.

The sign • is Changxingdao site and sign $\square$ is Yingkou site in Liaodong Bay.

\section{Data source and methodology}

The following section describes the data and methods used to examine the ice regime in relation to the investigated climate record. In this paper, the term sea ice is defined as the ice with more than $1 \mathrm{~cm}$ glacial ice. This includes large expanses of ice, as well as ice floes in study area. 
A joint winter field measurement as performed in a sea area $100 \mathrm{~m}$ from coast near Changxingdao $\left(121^{\circ} 24.703^{\prime} \mathrm{E}, 39^{\circ} 36.438^{\prime} \mathrm{N}\right)$ that in the location at northern Liaodong Bay (sign • in Fig. 1) for a period from January 27 to 30, 2003 in Liaodong Bay, Bohai Sea of China. The sea area is surrounded by seawater with a depth of $67 \mathrm{~cm}$, seawater temperature of $-1.67^{\circ} \mathrm{C}$ and air temperature of $-3.1^{\circ} \mathrm{C}$. The freezing point temperature of sea water in Liaodong Bay is $-1.4^{\circ} \mathrm{C}$. However due to the difference between air and water in their thermal characteristics, the corresponding air temperature of the freezing point in Liaodong Bay must lower than the freezing point of sea water, thus a thermal index of accumulated air temperature with $\leq-2{ }^{\circ} \mathrm{C}$ was selected in this paper, under consideration of ice growth and its duration (Gu et al., 2002).

The ice thickness was difficult to measure since the in situ ice field was normally an active drifting area. In Liaodong Bay, sea ice deposit in eastern coast and evacuated in western coast as both ocean currents and wind occurs from northern or northwestern direction. Because of the larger range of air temperature change occurred in Bohai Sea during winter of 2002/2003, the sea region of Changxingdao occurred three melt process before middle of January of 2003 , in which no fixed ice was formed in large scale. The major developing period of sea ice began from Jan. 16, 2003, and end until Jan. 30, 2003. The major ice type during the period was the piece of ice in asymmetry and neaped shape. Level ice with thickness of $2-40 \mathrm{~cm}$ distributed in small range in puddles and on deeper water paths near the coast. To understand the change of ice thickness with time and avoid the influence of land and ocean currents, a level ice region with an area of $30 \mathrm{~m}^{2}$ and an ice thickness of 5-20 cm was chosen at the investigated location. On 4:00 pm of Feb. 27, 2003, seven square ice holes was cut on the level ice region, which were ranked from coast to depth sea area and with the area of $40 \mathrm{~cm} \times 40 \mathrm{~cm}$. The holes were filled with seawater. Freezing time is defined at the zeroth hour and ice thickness formation at $0 \mathrm{~cm}$ at this time. The ice thickness measure began from this time until Jan. 30, 2003. The ice piece in the area of $10 \mathrm{~cm} \times 10 \mathrm{~cm}$ was taken out from the square ice hole and the mean ice thickness of the four corners was measured every hour. The mean thickness of the four corners was recorded as the average thickness of the ice piece at that time.

To understand the impact of different temperature on ice thickness, a temperature of ice surface (ATI), air temperature at $15 \mathrm{~cm}$ height above ice surface (ATO) and air temperature at $1.5 \mathrm{~m}$ height above land surface close coast (ATL) were measured at the same time by thermistor.

To know the weather condition accompanied by icing process, wind speed, wind direction and cloud cover were recorded at the same time. The near-surface incoming and reflected solar radiation was also measured. The ice salinity was determined from ice core samples.

The data quality was in general good, but some technical failures occurred during the experiment. The experiment was planned in order to for a better understanding the air-ice-sea interaction, to determine the heat exchange coefficients for establishing ice thickness model, to define the impact factors of the ice thermal processes and to accumulate data of albedo and salinity of sea water and sea ice in the region. 


\section{RESULTS}

Fig. 2 presents 1 -h-interval ice thickness growth during ice formation period, It was increased from 0 to $62 \mathrm{~cm}$; this period is denoted as minimum thickness of sea ice $(M I T H)$. Similarly, during another period of ice growth, it has grown from 0-70, and denoted as Maximum thickness of sea ice $(M A T H)$, and a growth of 0 to 68 is denoted as mean thickness of sea ice (METH). The increase of ice thickness, against durative time, obeyed a second-degree polynomial increasing correlation:

$$
\begin{aligned}
& \text { THICKNESS }=A X^{2}+B X+C_{0} \\
& R^{2}=0.9402-0.9655
\end{aligned}
$$

Where $C_{01}$ is the ice thickness at the initial interval of icing process, $A$ and $B$ is the regression coefficient of the second-degree polynomial. Under air temperature lower than the freezing point of $-2^{\circ} \mathrm{C}$, the ice thickness growth is proportional to time in a second-degree polynomial. Before $39^{\text {th }}$ hour, ice thickness increased very fast, with a speed of $1.5 \mathrm{~mm} / \mathrm{h}$, and after the $40^{\text {th }}$ hour, its growth speed had decreased and maintained at approximately $0.24 \mathrm{~mm} / \mathrm{h}$.

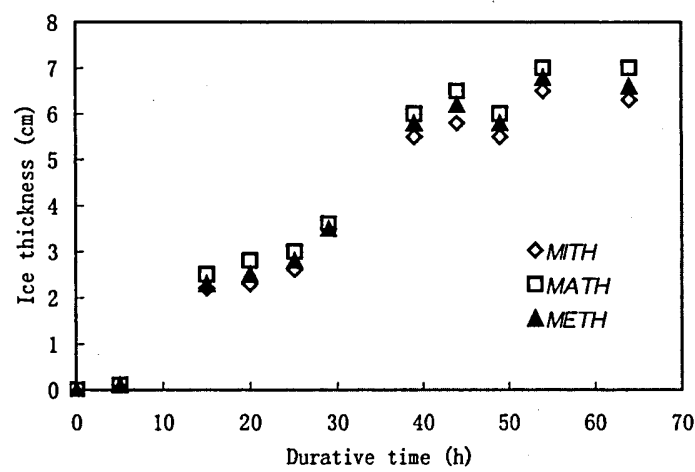

Fig. 2. The ice thickness deposition at different 1-hour intervals during observed period at study area. MITH, MATH, and METH represents the minimum ice thickness, the maximum ice thickness and mean ice thickness, respectively.

Because the start of ice formation and growth both needed on its freezing point and the duration in which data was taken the temperature was lower than the freezing point, a negative accumulative temperature (NAT) as a synthetical indicator was used to assess thermal process of sea ice thickness, which is a sum of accumulative temperatures lower than $-2{ }^{\circ} \mathrm{C}$.

The observed NAT decreased from 0 to $-202^{\circ} \mathrm{C}$ corresponding to ATI, from 0 to $-310^{\circ} \mathrm{C}$ corresponding to $A T O$, and from 0 to $-176{ }^{\circ} \mathrm{C}$ corresponding to $A T L$ (Fig. 3 ). The 
NAT decreased against duration, which obeyed a linear decay correlation:

$$
\begin{aligned}
& N A T=-D t+E_{0} \\
& R^{2}=0.6808-0.9247
\end{aligned}
$$

Where $E_{0}$ is the $N A T$ at the initial interval of freezing, and $D$ is the linear decay constant. Based on $R^{2}$ of $A T I, A T O$ and ATL, ATO relates to NAT the best relationship $\left(R^{2}=\right.$ 0.9247). Thus the ice thickness decrease in icing process could be explained by the constant decrease in accumulative temperature at a height $15 \mathrm{~cm}$ about ice surface (ATO) on the basic knowledge about the temperature gradients between the surface ocean and the atmosphere are greatest during winter (Ola, 2002). The surface heat and brine fluxes associated with sea ice growth contribution significantly to convection of the ocean and thermohaline circulation. The surface air temperature for computing the ice thickness is extracted from analyzed air temperature field (Rind, 1995).

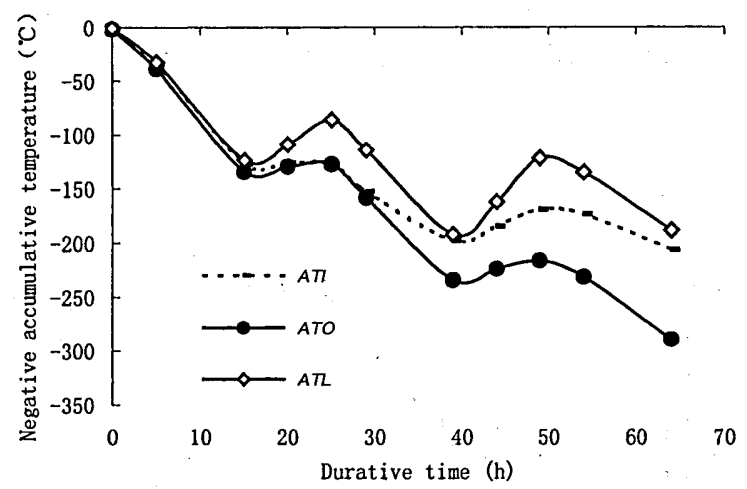

Fig. 3. Relationship of negative accumulating temperature $(N A T)$ and of freezing period under different temperature conditions.

The starting time $0 \mathrm{~h}$, was chosen as the beginning time of the squire ice hole was cut. ATI represents the temperature of ice surface; $A T O$ represents the air temperature at $15 \mathrm{~cm}$ height above ice surface, $A T L$ represents the air temperature at $1.5 \mathrm{~m}$ height above land surface close coast. Observation date: January 27-30, 2003.

To understand the relationship between ice thickness and negative accumulating temperature in the region, the negative accumulating temperature in different condition varying in height and location were analyzed (Fig. 4). Based on-linear relation between mean ice thickness and negative accumulating temperature of ATI, ATO and ATL, 2003, represented in as Fig. $4\left(\mathrm{a}_{1}, \mathrm{~b}_{1}\right.$ and $\left.\mathrm{c}_{1}\right)$, ATO represents a best linear correlation compared with that of $A T I$ and $A T L$. Namely, mean ice thickness could be obtained successfully by the air temperature at $15 \mathrm{~cm}$ height above ice surface (ATO) with $R^{2}=0.9262$. The increase of sea ice deposition mainly was governed by temperature and its duration. 
Hence, negative accumulating temperature was a better index for estimation of ice thickness.

According to Fig. $4\left(a_{1}, b_{1}\right.$ and $\left.c_{1}\right)$, air temperature at a height of $15 \mathrm{~cm}$ height above ice surface (ATO) shows the best correlation with highest correlation coefficient to ice thickness instead of the temperature of ice surface in 2003. To prove the relation further, a similar investigation was re-performed in Yingkou (sign — in Fig. 1), Feburary 9-13, 2004 , and the analytic results were shown in Fig. $5\left(a_{2}, b_{2}\right.$ and $\left.c_{2}\right)$. Similar to results obtained in 2003 investigation, the air temperature ATO had correlation coefficient of 0.9004 with ice thickness, which was also the highest one among the three kinds of temperature.

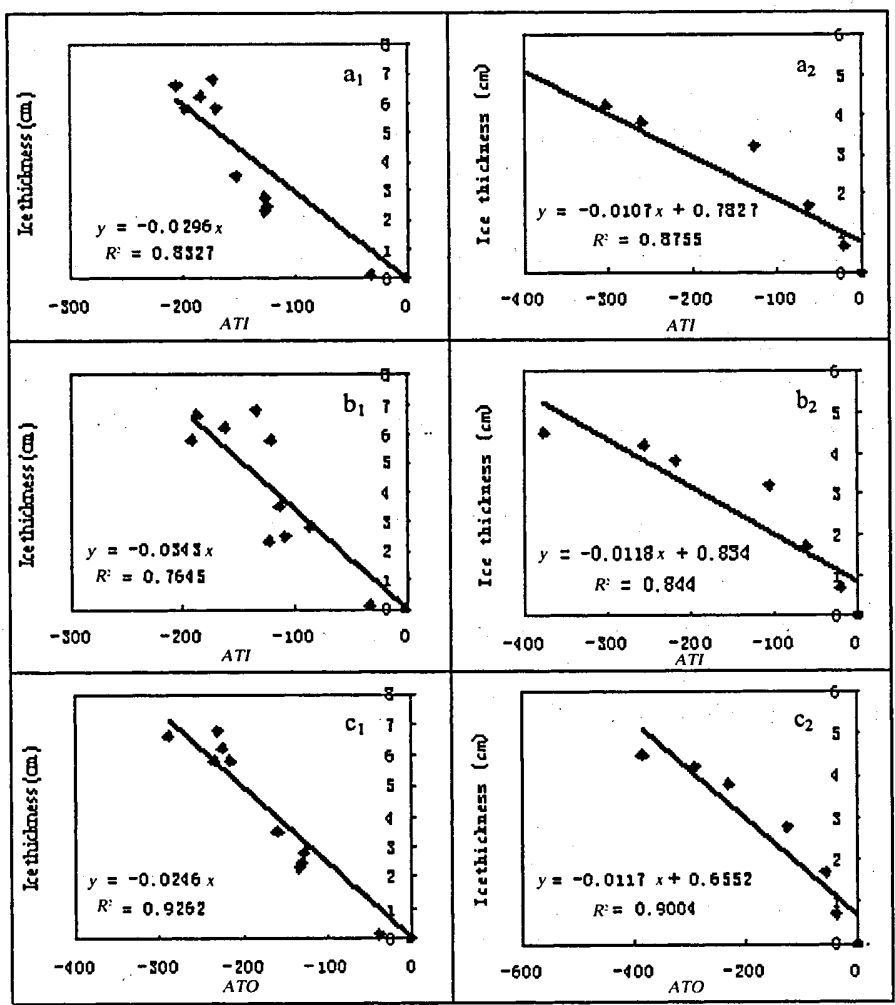

Fig. 4. The relationship between mean ice thickness and negative accumulation temperature in different environments.

Three figures in left side $\left(a_{1}, b_{1}\right.$, and $\left.c_{1}\right)$ represent the relationship at Changxingdao site, 2003. The figures in right side $\left(\mathrm{a}_{3}, \mathrm{~b}_{3}\right.$, and $\left.\mathrm{c}_{2}\right)$ represent the relationship at Yingkou, 2004. ATI represents temperature of ice surface; ATO represents the temperature at $15 \mathrm{~cm}$ height above ice surface, and $A T L$ represents air temperature at $1.5 \mathrm{~m}$ height above land surface close to coast. 
In this study, sea ice samples from observed site in Liaodong Bay were taken, and the parameters of icing process were observed and analyzed by measuring the ice thickness, temperature and durative freezing time as well as the synthetical thermal factor of accumulate temperature during winter season of 2003 and 2004 for the usage of sea ice as the fresh water. The ice growth phenomenon was consistent with a similar increase of negative accumulative temperature, The ice thickness, however, more linearly on air temperature above ice surface, while the process of ice formation was more persistent depending on duration of 39 hours.

\section{DISCUSSION}

Although ATO has the best correlation to mean ice thickness, and was in significant, the precision still needs to increase. The changing process of sea ice thickness is affected by other environmental factors. Probably, it is connected with the atmospheric circulation, clouds and precipitation. In addition, the characteristics of sea ice are related to geographic factors, including longitude, latitude, water depth and distance from coast. This conclusion is only elementary and tentative result to focus on the influence of air temperature on the sea ice thickness to find the surface factor for ice investigation in a larger scale ice using remote sensing method. To discover the changing characteristics of sea ice thickness influenced by all factors still need in-depth study, their roles have yet to be understood and formation the foci of future work. However, the result that temperature and durative freeze time are the important indicators of physical and thermal properties associated with sea ice occurrence and deposition was clearly indicated in the paper.

\section{ACKNOWLEDGEMENTS}

The authors sincere thank Prof. Peijun Shi for his coordination of the work and students of College of Resources Sciences and Technology, Beijing Normal University of China. The work was supported by NSFC, china (No. 40335048), and by 863 Ministry of Science and Technology, China (No. 2004AA24020).

\section{REFERENCES}

Allison, I., R. E. Brandt and S. G., Warren 1993 East Antarctic sea ice: albedo, thickness distribution, and snow cover. J. Geophys. Res., 98: 23417-12429

Arfeuille, G., L. A. Mysak and L. B. Tremblay 2000 Simulation of the interannual variability of the wind-driven Arctic sea-ice cover during 1958-1998. Climate Dynamics, 16: 107-121

Bao, C. L. 1999 Ocean Disaster and Forecast, Beijing, Beijing press

Cheng, B. 2002 On the modeling of sea ice thermodynamics and air ice coupling in the Bohai Sea and the Baltic Sea. Corpus of thesis of Finnish Institute of Marine Research-Contribution, 5: 1-5

Geng, S. Q., Y. L. Wang 2001 Change of atmospheric circumfluence in the northern hemisphere effect on climate and sea ice in winter of 2000-2001. J. Ocean Forecast, 18(3): 25-33

Gu, W., Q. Y. Zhang, F. Xie, N. Li and W. J. Cui 2003 Estimation of the amount of sea ice resources in Liaodong Bay by climate statistics. Journal of Natural Resources, 17(2): 9-16

Haapala, J. and M. Leppäranta 1996 Simulating the Baltic Sea ice season with a couple ice-ocean model. Tellus, 48 A: 622-643

Heveder, B. I. and M. N. Houssais 2001, Investigating the variability of the Arctic sea ice thickness in response to a stochastic thermodynamic atmospheric forcing. J. Climate Dynamics, 17: 107-125 
Ola, M. J., V. S. Elena and Martin W. M. 2002 Antarctic Sea-Ice processes and Climate-observed and modeled temperature and sea variability, Technical report, 218

Rind, D., R. Healy, C. Parkinson and D. Martinson 1995 The total influence of sea ice thickness and extent, Journal of Climate, 8: 449-463

Roland C. W. and W. F. Budd 2000 Derivation if ice thickness and bedrock topography in data-gap regions over Antarctica. Annuals of Glaciology, 31: 191-197

Rothrock, D. A, Y. Yu and G. A. Maykut 1999 Thinning of the Arctic sea-ice cover Geophysical Research Letters, 26: 3469-3472

Shi, P. J., Y. D. Fan, Hasi, Y. Yuan and F. Xie 2002 Estimate sea ice resources using data of AVHRR and MODIS- a case study of estimation of sea ice in Bohai Sea. Journal of Natural Resources, 17(2): 138-143

Shi. P. J., Hasi, J. H. Zhou and F. Xie 2002 Using seawater as the fresh water: saltnate machenism and utility value. Journal of Natural Resources, 17(3): 353-360

Tateyama, K. H. Enomoto 2001 Observation of sea-ice thickness fluctuation in the seasonal in-covered area during 1992 99 winters. Annals of Glaciology, 33: 449-456

Tina, Y. and O. J. Martin 2001 Sea-ice thickness and roughness in the Ross Sea, Antarctica. Annals of Glaciology, 33: 187-193

Wang, W. L. 2004 Government advisors, lawmakers propose ways to soothe thirst of nation, Xinhuanet $\operatorname{March} 9$

Worby, A. P. and C. A. Geiger 2002 Seasonal development of the sea-ice thickness distribution in East Antarctica: measurements from upward-looking sonar J. Annals of Glaciology, 33: 177-180

Wu, D. H. and H. Li 1999 Model and numerical forecast of sea ice sea J. Ocean bulletin, 16(3): 85-96

Wu, H. and Leppäranta 1988 On the modeling of ice drift in the Bohai Sea. -Finnnish Inst. Marine Res. Internal Report, 1-40

Wu, P. Z. 1992 Research and application of Sea Ice Remote Sensing Thesis[C], Beijing, Ocean press, pp. $73-82$

Xie, F. W. Gu, Y. Yuan and Y. H. Chen 2003 Estimation of sea ice resources in Liaodong Bay using remote sensing. Journal of Natural Resources, 17(2): 17-23 